\section{Desmoplastic Gangliocytoma}

Jacqueline L. Cunningham

Department of Psychology, CSH 021, The

Children's Hospital of Philadelphia, Philadelphia, PA, USA

\section{Synonyms}

Desmoplastic ganglioglioma

\section{Definition}

A variant of gangliogliomas, the desmoplastic ganglioglioma, or desmoplastic infantile ganglioglioma, is a rare intracranial tumor of mixed cell type, containing properties of both glial cells and neuronal cells. It is further characterized by the fibrosis forming in the vascular stroma (framework) of the tumor. The origin and cellular makeup of a desmoplastic gangliocytoma is incompletely understood. However, its derivation is thought to originate in multipotential cells found in the neural plate in the embryonic stage of human development. In patients younger than 2 years, the desmoplastic ganglioglioma presents as a large, cystic, often dura-attached mass. It usually occurs on one side of the, may grow large, and is most common in children younger than 1 year of age. Although it is usually of low grade, the desmoplastic ganglioglioma can be slow-growing, infiltrating, and become fatal in its progression. Surgery is the treatment of choice, with no complimentary treatment needed in cases of complete tumor resection. For cases that are inoperable, chemotherapy can be given.

\section{Cross-References}

Brain Tumor

- Ganglioglioma

$>$ Glioma

$>$ Neoplasms

\section{References and Readings}

Keating, R. F., Goodrich, J. T., \& Packer, R. J. (2001). Tumors of the pediatric central nervous system. New York: Thieme.

Pizzo, P. A., \& Poplack, D. G. (2005). Principles and practice of pediatric oncology (5th ed.). New York: Lippincott.

Tamburrini, G., Colosimo, C., Giangaspero, F., Riccardi, R., \& Di Rocco, C. (2003). Desmoplastic infantile ganglioglioma. Child's Nervous System, 19(5), 292-297. 